\title{
Experimental-Computational Investigation of Elastic Modulus of Ultra-High-Rise Pumping Concrete
}

\author{
Yue $\mathrm{Li}^{1}$, Ji Hao ${ }^{2}$, Zigeng Wang ${ }^{3 *}$, Zhongzheng Guan ${ }^{4}$, Rui Wang ${ }^{4}$, Heng Chen ${ }^{4}$ and Caiyun Jin ${ }^{5}$
}

\begin{abstract}
Based on the ultra-high-rise pumping concrete engineering test with pumping height of $407 \mathrm{~m}$ and maximum pumping pressure of 19.3 MPa, the variation of elastic modulus of the pumping concrete was analyzed by experiments and computational method. Firstly, the back scattered electron (BSE) image binarization method was used to study the effect of pumping on the composition and pore distribution of the concrete. The effects of the pumping process on the elastic modulus of the paste and interface transition zone (ITZ) were quantitatively evaluated by x-ray diffraction (XRD), back scattered electron energy dispersive spectroscopy (BSE-EDS) and homogenization method, and verified by the test results of nanoindentation. The results showed that the porosity of the paste after the ultra-high-rise pumping decreased by $7.27 \%$, the hydration degree of the cement increased by $6.51 \%$, and the elastic modulus of the paste increased by $3.1 \mathrm{GPa}$. For the ITZ of the sand, the porosity decreased by $5.3 \mu \mathrm{m}$, the average porosity decreased by $15.78 \%$, and the elastic modulus increased by $7.7 \mathrm{GPa}$. For the ITZ of the gravel, the thickness decreased by $6.91 \mu \mathrm{m}$, the average porosity decreased by $16.34 \%$, and the elastic modulus increased by $10.2 \mathrm{GPa}$. Therefore, the effect of the ultra-high-rise pumping on the ITZ was significantly larger than that of the paste in the concrete. Afterward, the computational method was proposed as the combination of the homogenization method and the Lu and Torquato model. As the result, the elastic modulus of concrete after ultra-high-rise pumping can be precisely predicted on the micro-meso-macro scale due to the promising agreement between the experimental measurements and the numerical results.
\end{abstract}

\section{Introduction}

With the emergence of a large number of ultra-high-rise buildings around the world, the pumping height of concrete keeps creating new records and the technology of the ultra-high-rise pumping concrete has been evolving continuously (Kaplan et al. 2005; Tan et al. 2011). U1tra-high-rise buildings, as landmark constructions in many countries, have strict requirements on the structure and mechanical properties of the concrete materials at micro and macro levels. Influenced by factors such as high pumping pressure and long pumping flow time, the ultra-high-rise pumping concrete showed different flow

${ }^{1}$ Professor, The Key Laboratory of Urban Security and Disaster Engineering, Beijing Key Laboratory of Earthquake Engineering and Structural Retrofit, Beijing University of Technology, Beijing, 100124, China.

${ }^{2} \mathrm{Ph}$.D candidate, College of Materials Science and Engineering, Beijing University of Technology, Beijing, 100124, China.

${ }^{3}$ Assistant Professor, The Key Laboratory of Urban Security and Disaster Engineering, Beijing University of Technology, Beijing, 100124, China.

*Corresponding author, E-mail: zigengw@bjut.edu.cn

${ }^{4}$ Research Assistant, The Key Laboratory of Urban Security and Disaster Engineering, Beijing University of Technology, Beijing, 100124, China.

${ }^{5}$ Lecturer, College of Applied Sciences, Beijing University of Technology, 100124, China. patterns and hardening properties before and after pumping (Ede 1957; Choi et al. 2014). Therefore, it is an important research topic to clarify the influence of the pumping action on the structure and compositions of the concrete at micro, meso and macro scales.

Most of the research on the pumping concrete focused on the calculation and numerical simulation of the flowability and rheological properties of the fresh concrete, the composition and thickness of the lubricating layer and the pumping pressure loss (Tan et al. 2011). Feys et al. $(2012,2014)$ studied the rheological behavior of self-compacting concrete before and after pumping by pumping circuit test. The results showed that the viscosity of the concrete decreased with the increase of pumping pressure and flow rate. Besides, influenced by the dispersing effect of admixtures on cement particles during the pumping process, the yield strength of the fresh concrete increased whereas the plastic viscosity decreased. Choi et al. (2013) compared the composition of the concrete before and after pumping, concluding that the hydration degree of the concrete increased, and the air content decrease. As known, there were many factors affecting the strength and elastic modulus of the hardened concrete, such as the material mix ratio (Choi et al. 2014; Zhao et al. 2018), curing environment and age (Ortega et al. 2012). As pumping is an indispensable method of transportation for concrete engineering, its influence on the elastic modulus of the concrete cannot be ignored (Choi et al. 2013). Since pumping affects the pore distribution and hydration degree of the concrete directly, the mechanical properties will vary inevitably 
Table 1 Chemical compositions (weight \%) and basic properties of cementitious materials.

\begin{tabular}{ccccc}
\hline Chemical composition & Cement & Fly ash & Ultrafine slag & Silica fume \\
\hline $\mathrm{SiO}_{2}$ & 23.6 & 52.3 & 45.7 & 92.7 \\
$\mathrm{Al}_{2} \mathrm{O}_{3}$ & 4.4 & 29.7 & 5.8 & 0.3 \\
$\mathrm{Fe}_{2} \mathrm{O}_{3}$ & 2.3 & 6.5 & 46.6 & 0.7 \\
$\mathrm{CaO}$ & 67.5 & 11.2 & 1.2 & 0.8 \\
$\mathrm{SO}_{3}$ & 2.03 & 1.5 & 0.26 & 0.0 \\
Ignition loss & 4.08 & 3.7 & 2.81 & 4.0 \\
Density g/cm & 3.10 & 2.78 & & 2.20 \\
\hline
\end{tabular}

Table 2 Mixture proportions of pumping concrete $\left(\mathrm{kg} / \mathrm{m}^{3}\right)$.

\begin{tabular}{cccccccc}
\hline Water & Cement & Fly ash & Slag & Silica fume & Sands & Gravel & HRWRA \\
\hline 181.5 & 320 & 150 & 100 & 35 & 780 & 890 & 14.7 \\
\hline
\end{tabular}

(Choi et al. 2013). At present, there is no in-depth study on the effect of the ultra-high-rise pumping on the elastic modulus of the concrete.

In this study, the authors creatively proposed an experimental-computational method to investigate the variation characteristics of the elastic modulus of the ultra-high-rise pumping concrete. On the side of the experiments, based on the pumping test in an ultra-high-rise building during the construction process, the influence on the micro-composition and structure of the pumping concrete was determined by the back scattered electron (BSE) image binarization analysis method and the nanoindentation test. On the side of the computation analysis, for the first time, the elastic modulus of the ultra-high-rise pumping concrete was predicted by the homogenization method combined with $\mathrm{x}$-ray diffraction (XRD), back scattered electron energy dispersive spectroscopy (BSE-EDS), quantitative analysis method and BSE image binary analysis method on the micro-meso-macro scale. The research route is shown in Fig. 1.

\section{Materials and test methods}

\subsection{Materials}

In this paper, P.II 42.5 type ordinary Portland cement, class I fly ash, S95 superfine slag powder and superfine silica fume were used as the cementitious materials. The chemical compositions and basic properties of the cement, fly ash, slag and silica fume are shown in Table 1. The sand was with the fineness modulus of 2.8 , mud content of $1 \%$, apparent density of $2582 \mathrm{~kg} / \mathrm{m}^{3}$ and maximum particle size of $4.75 \mathrm{~mm}$. The gradation of the gravel was 5 to $16 \mathrm{~mm}$, the mud content was $0.3 \%$, the crushing index was $7 \%$, and the needle flake content was $4 \%$. A polycarboxylate-based high range water reducing admixtures (HRWRA) with the water reducing rate of $27 \%$, PH value of 8.3 , density of $1.057 \mathrm{~g} / \mathrm{cm}^{3}$ and solid content of $15.6 \%$ was adopted. Table 2 shows the mix ratios of the concrete for the ultra-high-rise building engineering.

\subsection{Pumping project}

The pumping concrete engineering test was carried out

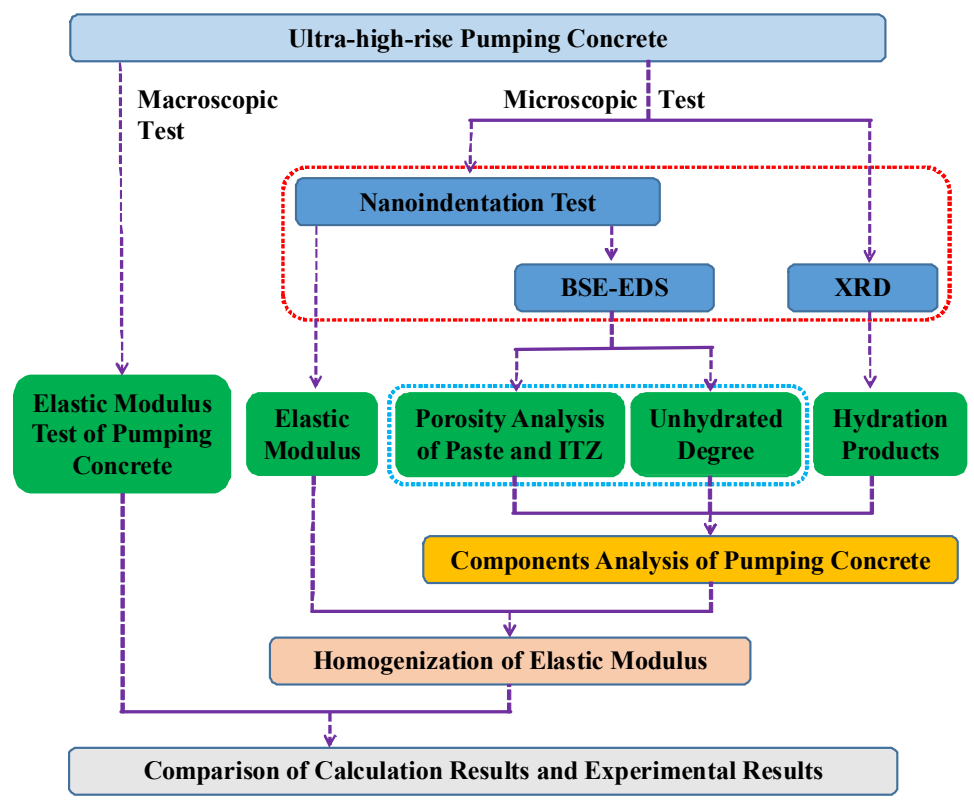

Fig. 1 Roadmap of this paper. 
on an ultra-high-rise building in Wuhan, China. The ultra-high-rise building had 125 floors above the ground with a designed height of $636 \mathrm{~m}$. The pumping test was conducted using the pumping system of the ultra-high-rise building. The pumping power was provided by an ultra-high-pressure concrete pump HBT90.48.572RS with a maximum pumping pressure reaching $48 \mathrm{MPa}$. The pumping system consisted of the horizontal pumping pipe with a length of $66 \mathrm{~m}$ and the vertical pumping pipe with a height of $407 \mathrm{~m}$. The inner diameter and outer diameter of all the pipes were $150 \mathrm{~mm}$ and $168 \mathrm{~mm}$, respectively. The pumping flow rate was $30 \mathrm{~m}^{3} / \mathrm{h}$, and the average flow rate was $0.47 \mathrm{~m} / \mathrm{s}$. When the pumping height was $407 \mathrm{~m}$, the pumping period of the concrete in the pump pipe was $28 \mathrm{~min}$. The pumping outlet pressure was in the range of $18.6 \mathrm{MPa}$ to $19.8 \mathrm{MPa}$. When the flow velocity of the pumping concrete was stable, the pump pressure was $19.3 \mathrm{MPa}$. The pumping water, paste and mortar were used to pre-wet the pipes in turn before the pumping concrete test (the amount of the cementitious materials and water used in the paste and mortar were the same as that of the concrete, and the mortar also used the same HRWRA as the concrete with a content of $1 \%$ ). Pre-wetting can form a stable lubricating layer near the pipe wall before pumping the concrete so as to reduce the resistance of the concrete and the pipe during initial pumping. The concrete was sampled from the inlet and outlet of the pumping pipe when the pumping pressure was stable.

Before pumping, the slump and the slump flow of the concrete were $270 \mathrm{~mm}$ and $700 \mathrm{~mm}$. After pumping, the slump and the slump flow of the concrete were $250 \mathrm{~mm}$ and $600 \mathrm{~mm}$.

\subsection{Methods}

\subsubsection{Sample preparation}

In this paper, four different experiments were conducted, including the static compressive elastic modulus test, XRD test, nanoindentation test and BSE-EDS test.

The concrete used in the static compressive elastic modulus test before and after the pumping was poured into mold with a dimension of $150 \times 150 \times 300 \mathrm{~mm}$. After the standard curing (temperature of $20^{\circ} \mathrm{C}$ and relative humidity of $95 \%$.) of $28 \mathrm{~d}$, the samples were air-dried naturally for 24 hours at $20^{\circ} \mathrm{C}$ at indoor environment. The flatness of the two ends of the sample was processed, then the midline was drawn on both sides of the sample to determine the location of the dial gauges.

Like the static compressive elastic modulus test above, the concrete before and after pumping was poured into cubic samples $\left(100 \times 100 \times 100 \mathrm{~mm}^{3}\right)$ for the XRD test. After the standard curing of $28 \mathrm{~d}$ and natural air drying of $24 \mathrm{~h}, 50 \mathrm{~g}$ paste sample was drilled from the concrete, ground into powder in an agate mortar until the powder can pass through the $80 \mu \mathrm{m}$ square-hole sieve.

The samples for the nanoindentation test were the aggregates with ITZs cut off from the concrete cubic samples. These samples were pretreated due to the high surface smoothness requirement of the test (Zhao et al. 2005; Han et al. 2012). Firstly, alcohol was sprayed on the surface of the samples to prevent further hydration. Then the samples were placed into a cold-inlaid die, poured with epoxy resin. After that, the samples were polished with 400 mesh, 800 mesh, 1200 mesh and 2500 mesh sandpaper on the grinding and polishing machine. During the grinding process, the upper and lower planes must be parallel. Then the samples were polished with $0.25 \mu \mathrm{m}$ diamond suspension with canvas and silk cloth in turn. The surface roughness of the polished sample was analyzed by the atomic force microscopy (AFM). When the surface roughness was less than $100 \mathrm{~nm}$, the polishing requirements were met. Finally, the polished samples were cleaned with anhydrous ethanol for 15 minutes in an ultrasonic cleaner to remove the polishing machine particles or sample powder adsorbed on the surface, and then the samples were dried naturally. Figure 2 is a sample ready for the nanoindentation test with a thickness of about $7 \mathrm{~mm}$.

BSE-EDS test can directly use the nanoindentation test samples without additional treatment.

\subsubsection{Static compressive elastic modulus test}

The macroscopic static compressive elastic modulus test of the pumping concrete was carried out in accordance with the GB50081-2002 specification, shown in Fig. 3. Two dial gauges were arranged $75 \mathrm{~mm}$ away from the end of the sample to measure the deformation under loading. The loading speed of the test was $0.3 \mathrm{MPa} / \mathrm{s}$. In this paper, the axial compressive strength and the elastic modulus of the pumping concrete were calculated according to the arithmetic average of six measured values.

\subsubsection{XRD analysis}

The XRD-7000 X-ray Powder Diffraction of Shimadzu

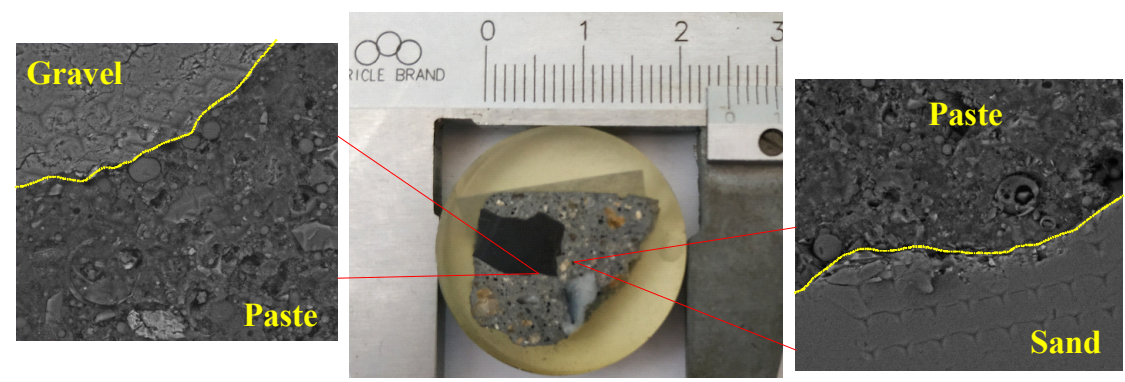

Fig. 2 Sample for nanoindentation test. 
Table 3 Mechanical properties of concrete before and after pumping.

\begin{tabular}{ccccc}
\hline & \multicolumn{2}{c}{ Before pumping } & \multicolumn{2}{c}{ After pumping } \\
\cline { 2 - 5 } & $f_{\mathrm{cp}}$ & $E$ & $f_{\mathrm{cp}}$ & $E$ \\
\hline Average value & $55.6 \mathrm{MPa}$ & $39.9 \mathrm{GPa}$ & $59.6 \mathrm{MPa}$ & $43.3 \mathrm{GPa}$ \\
Standard deviation & 1.09 & 1.49 & 1.09 & 0.96 \\
\hline
\end{tabular}

Company, Japan was used, driven by two independent axes. It can be set by the $\theta-2 \theta$ linkage drive or $\theta$ and $2 \theta$ axis independently. The scanning angle range was $-6^{\circ}$ to $+163^{\circ}(2 \theta)$. The powder to be measured was pressed on a special glass sample plate for the diffractometer, then carried out by the XRD test.

\subsubsection{Nanoindentation test}

The nanoindentation test was carried out by G200 nanoindentation instrument produced by Agilent Company, USA. The hardness and elastic modulus of the sample varying with depth were measured by continuous stiffness method (CSM). During the loading process, the sample first underwent the elastic deformation. With the increase of load, the sample began to undergo the plastic deformation, and the loading curve was non-linear. The unloading curve reflected the elastic recovery process of the measured object. The hardness and elastic modulus of each test point can be obtained by analyzing the loading and unloading curve. According to Oliver-Pharr principle (Wang et al. 2009), the hardness $H$ and elastic modulus $E$ of the test point can be calculated by Eq. (1) and Eq. (2).

$$
\begin{aligned}
& H=P / A \\
& E_{r}=\frac{\sqrt{\pi}}{2 \beta} \frac{S}{\sqrt{A}}
\end{aligned}
$$

where $P$ is the peak value of the corresponding curve of the maximum load, $A$ is the contact area at the maximum load, $S$ is the contact stiffness $\left[S=(\mathrm{d} P / \mathrm{d} h)_{h=h_{\max }}\right]$ and the upper part (elastic section) of the unloading curve is usually used for fitting analysis. $\beta$ is the pressure head

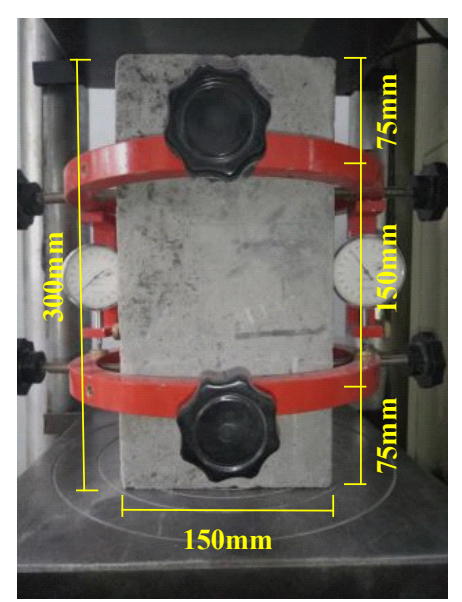

Fig. 3 Test of elastic modulus of concrete. correction coefficient, for Berkovich pressure head (the angle between the center line and the side is 65.35 degrees of triangular pyramid), $\beta=1.034$ and $E_{r}$ is the effective elastic modulus defined by Eq. (3).

$$
\frac{1}{E_{r}}=\frac{1-v^{2}}{E}+\frac{1-v_{i}^{2}}{E_{i}}
$$

where $E$ and $v$ represent the elastic modulus and Poisson's ratio of the tested materials, respectively. For cement-based materials, Poisson's ratio $v$ is $0.25 . E_{i}$ and $v_{i}$ are the elastic modulus and Poisson's ratio of the nanoindenter, respectively. For diamond nanoindenter adopted in this study, $E_{i}$ and $v_{i}$ are $1141 \mathrm{GPa}$ and 0.07, respectively.

In this paper, nanoindentation tests were carried out on paste, sand ITZ and gravel ITZ of the concrete samples before and after pumping. In order to avoid the influence of the adjacent aggregates on the tested area, the nanoindentation test of the ITZ was conducted on the edge of the aggregates with spacing greater than $500 \mu \mathrm{m}$ from the adjacent aggregates. An $8 \times 8$ array was carried out in the selected marked area with the nanoindentation depth of $2000 \mathrm{~nm}$ and nanoindentation spacing of $15 \mu \mathrm{m}$. The nanoindentation depth was set to $2000 \mathrm{~nm}$ so that the point can be clearly observed under the Scanning Electron Microscope (SEM). The spacing of the point was set to $15 \mu \mathrm{m}$ with the purpose of arranging the points densely enough and maximizing the chance that the points fell in the area near the ITZ.

\subsubsection{BSE-EDS analysis}

The nanoindentation samples were sprayed with gold directly, then tested by the BSE-EDS. The Field Emission Environment SEM (Quanta250 FEG SEM) and EDS with $130 \mathrm{eV}$ resolution were used in the experiment. The point-by-point BSE and EDS analysis were performed on the nanoindentation samples. The back-scattering working environment was under a low vacuum of $60 \mathrm{~Pa}$, and the accelerating voltage used was all $20 \mathrm{kV}$. The same contrast and brightness were maintained in the image acquisition of the samples in the same age period so as to ensure the consistency of the image grayscale and the repeatability of the test.

\section{Experimental results}

3.1 Macroscopic elastic modulus test of concrete The uniaxial compressive strength $\left(f_{\mathrm{cp}}\right)$ and elastic modulus $(E)$ of concrete before and after pumping are shown in Table 3. After pumping, the $f_{\text {cp }}$ and $E$ of concrete increased by $7.19 \%$ and $8.52 \%$. 


\subsection{XRD analysis}

Figure 4 is the XRD result of the paste in the pumping concrete for $28 \mathrm{~d}$. The results showed that the paste contained $2 \mathrm{CaO} \cdot \mathrm{SiO}_{2}$, reaction product $\mathrm{Ca}(\mathrm{OH})_{2}$ and some unreacted mineral admixture, such as mullite $\left(\mathrm{Al}_{2} \mathrm{O}_{3} \cdot 2 \mathrm{SiO}_{2}\right)$ and unhydrated silica $\left(\mathrm{SiO}_{2}\right)$. It was generally believed that the C-S-H gel was one type of the amorphous substance and cannot be detected by XRD (Han et al. 2016).

\subsection{BSE-EDS results}

In this paper, the atomic percentages of each nanoindentation point were determined by the energy spectrum analysis, and then the proportions of the hydration products at each point were calculated. Figure $\mathbf{5}$ is the partial EDS result of the gravel ITZ after pumping. Point 1 was located on the fly ash, which contained the elements of $\mathrm{O}, \mathrm{Al}$ and $\mathrm{Si}$. Point 2 contained the elements of $\mathrm{C}, \mathrm{O}$ and $\mathrm{Ca}$, indicating it located on the gravel. Point 3 contained the elements of $\mathrm{O}, \mathrm{Al}, \mathrm{Si}$ and $\mathrm{Ca}$, meaning it was the paste. Point 4 was the unhydrated cement particles, which contained the elements of $\mathrm{O}, \mathrm{Si}$ and $\mathrm{Ca}$. When the point was on the sand, only the elements of $\mathrm{O}$ and Si could be detected.

\subsection{Analysis of unhydrated cement and porosity of paste}

In the BSE image of the paste at the age of $28 \mathrm{~d}$, according to the gray eigenvalues of different phases, the percentages of phases were calculated by threshold segmentation using the Avizo image analysis software.
Then the volume fractions of the porosity and the unhydrated cement particles in the sample were calculated (Qing-Lei et al. 2008).

In order to accurately distinguish the unhydrated cement and pore in the paste, the segmentation threshold of the unhydrated cement was set to the range 165 to 250 and the segmentation threshold of the pore was set to the range 0 to 25 , indicating that the segmentation threshold of the hydration products was 25 to 165 (Kocaba et al. 2012). The gray distribution of pores, hydration products and unhydrated cement particles is shown in Fig. $6(\mathrm{Hu}$ et al. 2017a). In order to avoid the uncertainty caused by one BSE region, 100 regions were randomly selected for test analysis for each sample with the 2000 times magnification of the scanning region. The percentage of the unhydrated particles in each region was calculated first,

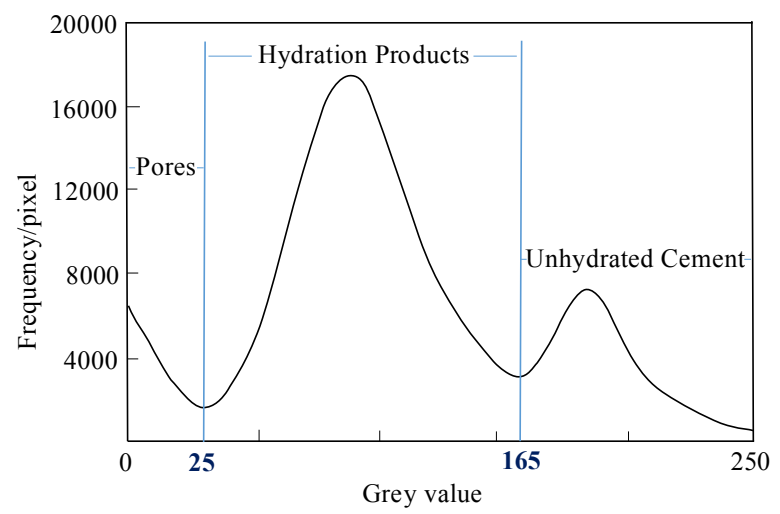

Fig. 6 Gray Distribution map of paste in BSE image.

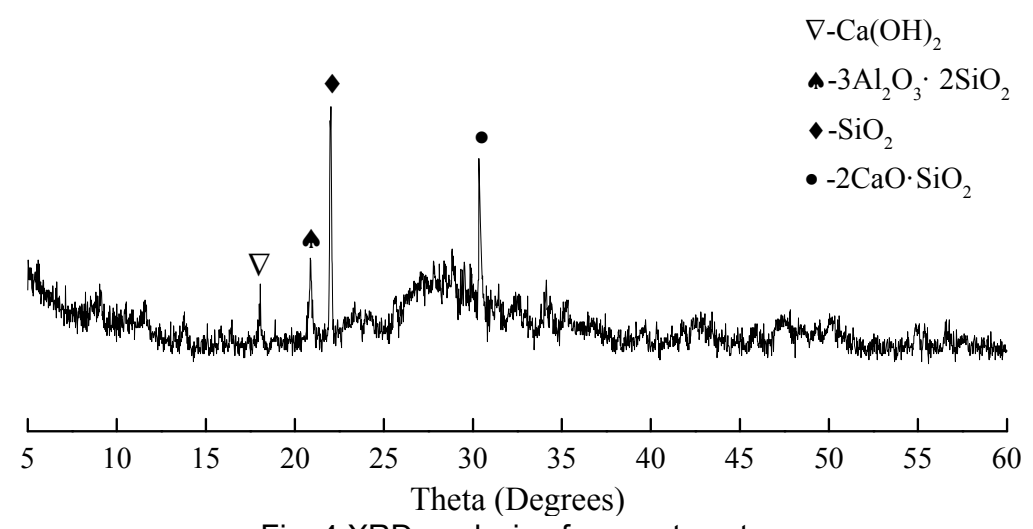

Fig. 4 XRD analysis of cement paste.

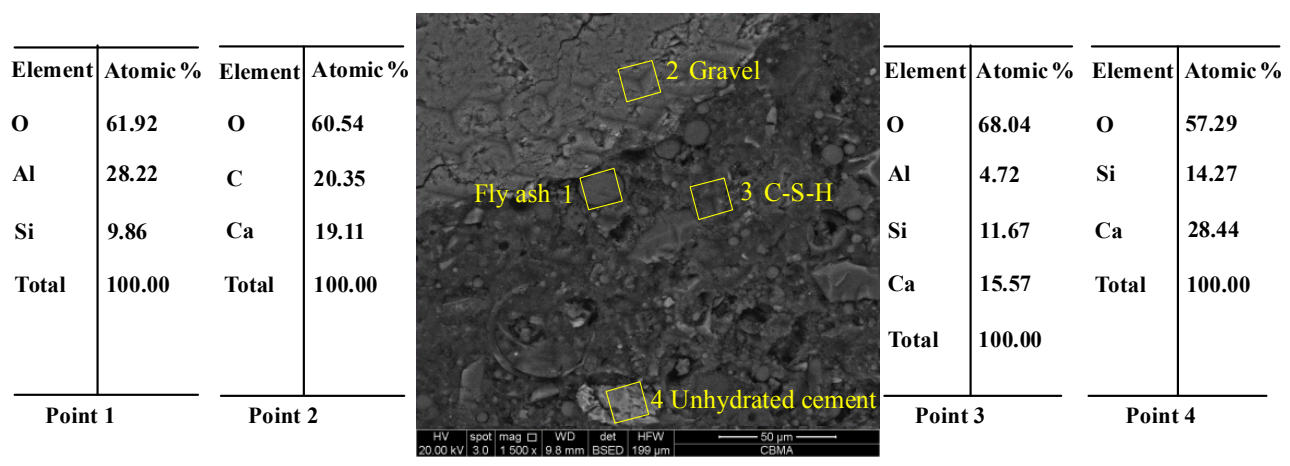

Fig. 5 EDS analysis of nanoindentation points. 
and then the average value of the 100 regions was taken as the volume ratio of the unhydrated cement of the sample.

Figures 7(a) and (b) are BSE images of the paste before and after pumping. The purple part is the unhydrated cement particles after threshold segmentation. The rest are the hydration product and the pore. According to the pixel number of the unhydrated cement particles and the paste, the volume ratio of the unhydrated cement in the image area can be calculated by Eq. (4).

$$
\varphi_{u n}=\frac{n_{u n}}{n} \times 100 \%
$$

where $\varphi_{u n}$ is the volume ratio of the unhydrated cement, $n_{u n}$ is the pixel number of the unhydrated cement, and $n$ is the pixel number of the cement paste.

The volume ratio of the unhydrated cement in paste before pumping in Fig. 7(a) was $12.42 \%$, and that in paste after pumping in Fig. 7(b) was $4.71 \%$. After calculating the average value of the 100 regions, the volume ratio of the unhydrated cement before pumping was $11.78 \%$ with the standard deviation of 4.37 . The volume ratio after pumping was $5.27 \%$ with the standard deviation of 3.72. Therefore, the unhydrated cement in paste decreased by $6.51 \%$ after pumping.

Figure 8 is the binarization analysis of the porosity of the paste before and after pumping. The blue part is the pore and the rest are the unhydrated cement and the hydration product. According to the pixel number of the pore and the paste, the porosity in the BSE image area can be calculated with Eq. (5).

$$
\varphi_{p}=\frac{n_{p}}{n} \times 100 \%
$$

where $\varphi_{p}$ is the porosity of the sample, and $n_{p}$ is the pixel number of the pore.

The porosity of the paste before and after pumping in Figs. 8(a) and (b) were $10.89 \%$ and $4.70 \%$, respectively. The average porosities of the paste before and after pumping were $11.73 \%$ and $4.46 \%$ with standard devia-

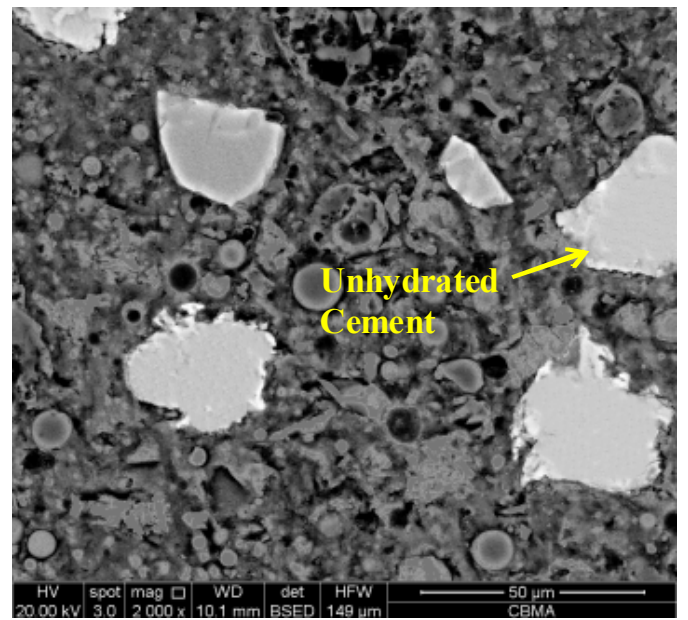

(a) Before pumping

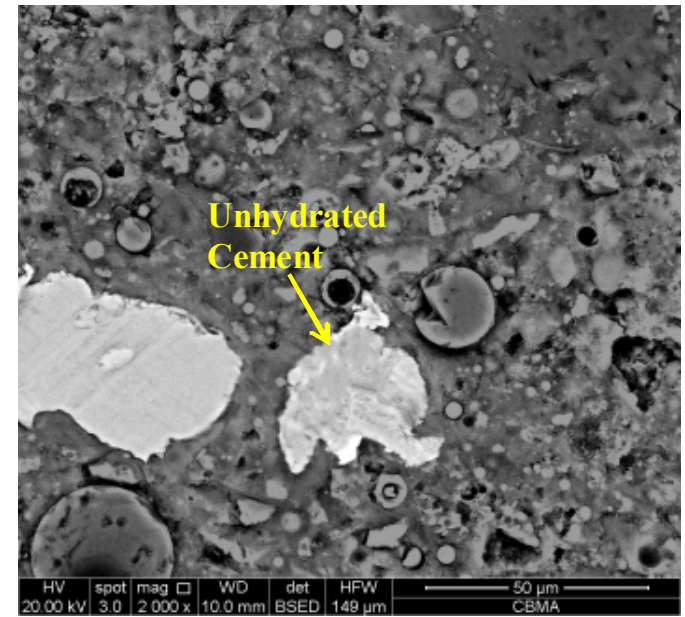

(b) After pumping

Fig. 7 Binarization analysis of unhydrated cement.

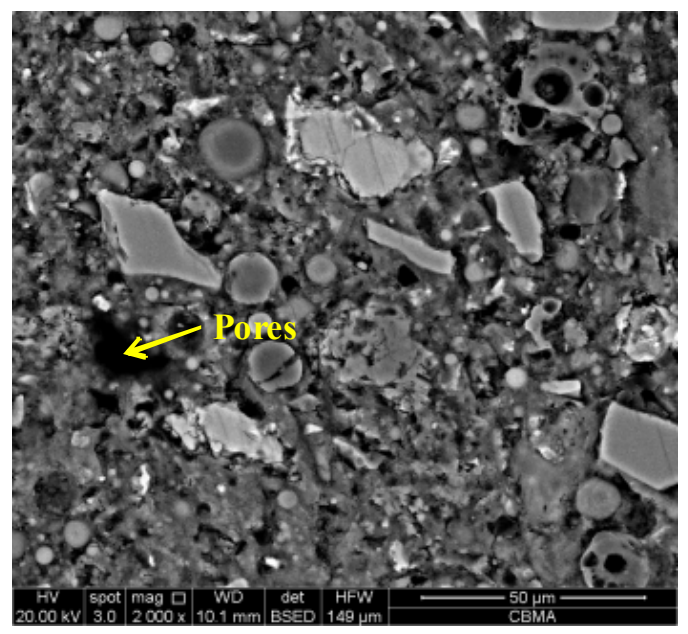

(a) Before pumping

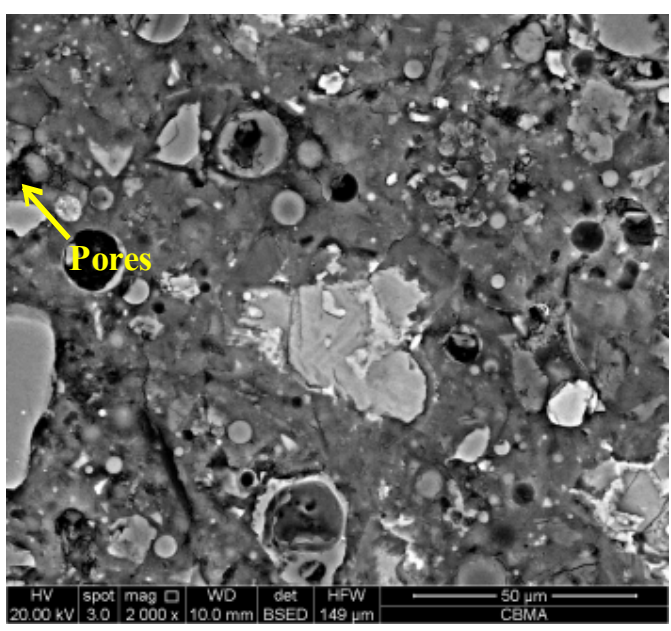

(b) After pumping

Fig. 8 Binarization analysis of paste porosity. 
tions of 1.23 and 1.28 , respectively. Hence, after pumping, the porosity of the paste decreased by $7.27 \%$ (= $11.73 \%-4.46 \%)$ and the matrix became more compact.

\subsection{ITZ thickness of pumping concrete}

When the cement grains encounter the "wall" of the aggregate, a region of higher porosity near the aggregate surface will appear, due to the "packing" constraints imposed by the aggregate surface (Li et al. 2017). In this paper, the thickness of the ITZ was determined by analyzing the porosity of the ITZ in the BSE image. For each sample, 30 ITZs were randomly selected, and the average value of the porosity was considered as the value of the ITZ. Figure 9 is the BSE image of one sand ITZ before and after pumping. The paste was divided into six stripes with a width of $7.5 \mu \mathrm{m}$ along the sand edge, numbered as I, II, III, IV, V and VI in turn. Then the BSE image binarization method was used to perform the threshold segmentation for the pores in the six regions. The porosity of each region was calculated by Eq. (5).

Figure 9(a) is the porosity analysis of the sand ITZ before pumping. The porosities decreased with the increase of the distance to the edge of the sand. The porosities in area V and VI were close to the average porosity $(11.73 \%)$ of the paste before pumping. The porosities of the sand ITZ after pumping is shown in Fig. 9(b). The porosity of the area IV, V and VI was close to the average porosity $(4.46 \%)$ of the paste after pumping. Therefore, the porosity of the sand ITZ after pumping was quite different from that before pumping.

According to the average values of the porosities in areas I, II, III, IV, V and VI of 30 samples, the porosity curves of the sand ITZ before and after pumping were drawn in Fig. 10. When the slope of the curve was close to 0 , the porosity of the corresponding point was close to the paste, meaning that the point was already in the paste instead of the ITZ.

The porosity curves before and after pumping can be divided into two parts: the descending section and the horizontal section. The descending section corresponded

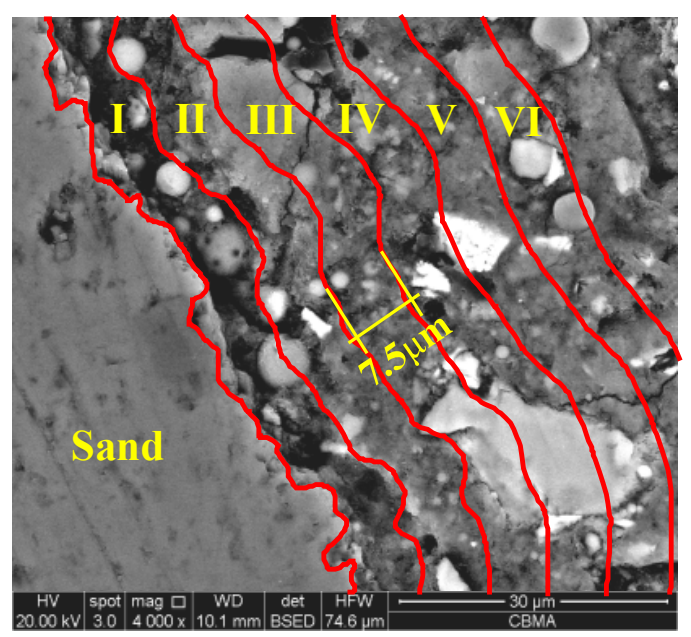

(a) Before pumping to the ITZ, and the horizontal section indicated that the porosity in this area was the same as that of the paste. The linear expression of the descending section was obtained by linear fitting the points of the descending section, and the value of the horizontal line was the same as that of the porosity of the paste. When the descending section intersected with the horizontal section, the ITZ of the aggregate can be considered to have ended (Gao et al. 2013), which meant the thickness of the ITZ was the distance between the edge of the aggregate and the intersection of the descending section and the horizontal line. According to the method above, the thickness of the sand ITZ before and after pumping was $28.47 \mu \mathrm{m}$ and $23.17 \mu \mathrm{m}$. In this paper, the average porosity was used to represent the porosity in the ITZ. The average porosity of the ITZ was calculated by integrating the porosity curve in the ITZ section, then divided by the thickness of the ITZ. The average porosity of the sand ITZ before pumping was $23.84 \%$ and that of the sand ITZ after pumping was $7.40 \%$.

The same method was used to determine the porosity of the gravel ITZ of the pumping concrete, shown in Fig. 11.

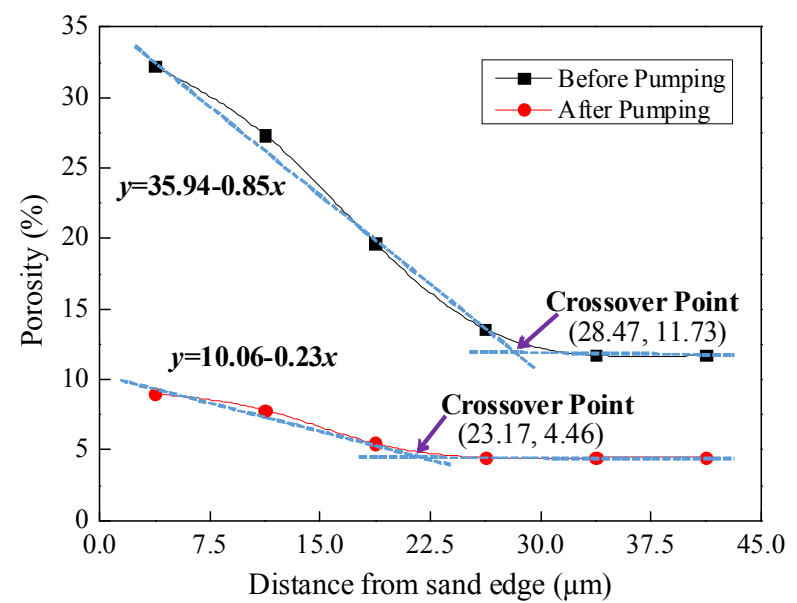

Fig. 10 Porosity curve of sand ITZ.

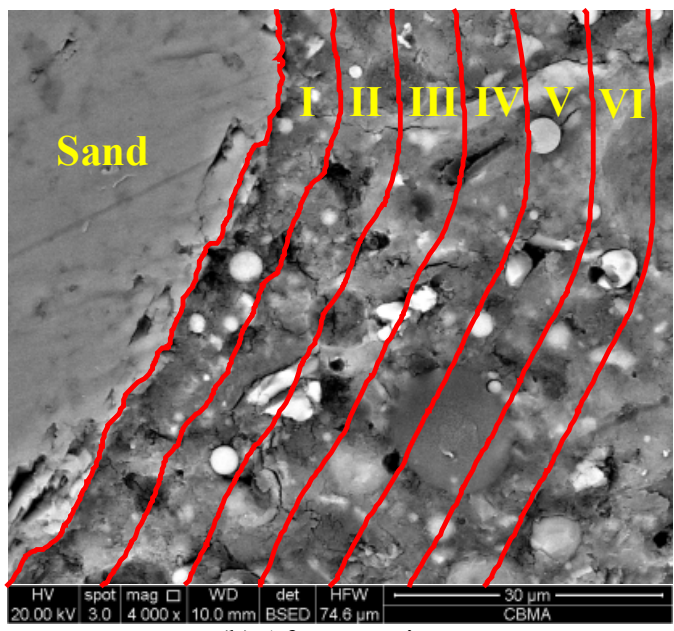

(b) After pumping

Fig. 9 Porosity analysis of sand ITZ. 
The porosity curves of the gravel ITZ before and after pumping were drawn in Fig. 12. The thickness of the gravel ITZ was $29.69 \mu \mathrm{m}$ before pumping and $22.78 \mu \mathrm{m}$ after pumping. The average porosity of the gravel ITZ

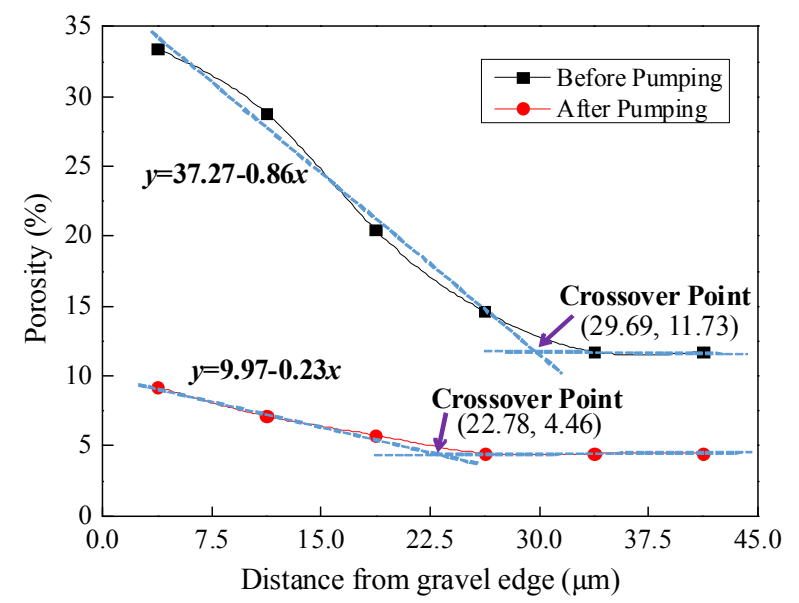

Fig. 12 Porosity curve of gravel ITZ.

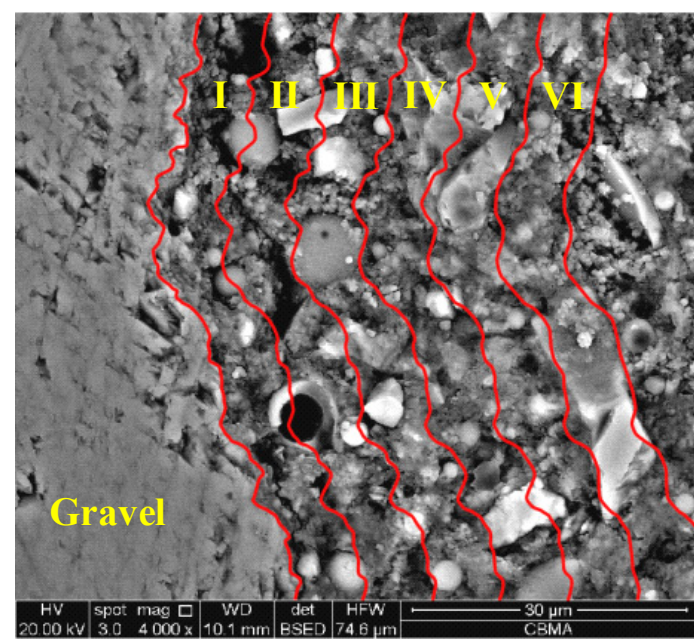

(a) Before pumping before pumping was $24.50 \%$, and that of the gravel ITZ after pumping was $7.35 \%$. It was concluded that the variation trend of the sand ITZ and the gravel ITZ before and after pumping was similar.

After pumping, the porosity of matrix and ITZ in concrete decreased. The reason was that the hydration degree of cement increased after ultra-high-rise pumping, which consumed the free water in the cement slurry and reduced the number of pores caused by the free water (Choi et al. 2013). On the other hand, the bubbles were easily broken and overflowed under ultra-high-rise pumping, thereby reducing the porosity in the concrete after pumping.

\subsection{Nanoindentation results of paste and ITZ}

The nanoindentation test was carried out on the paste and the ITZ to study the pumping effect on the elastic modulus of the concrete. Figure 13 is a sketch map of $4 \times 4$ nanoindentation results of the paste before and after pumping. The blue part is the unhydrated cement particles and the white part is the pores. The elastic modulus

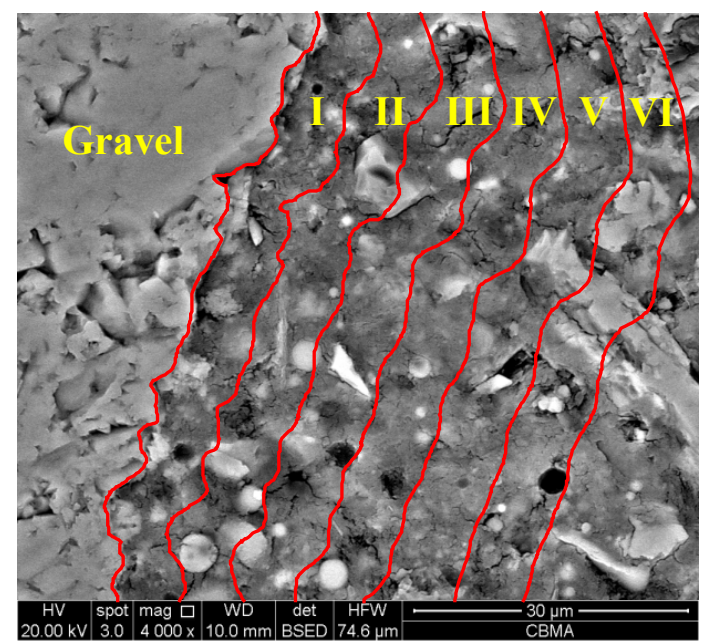

(b) After pumping

Fig. 11 Porosity analysis of gravel IT.

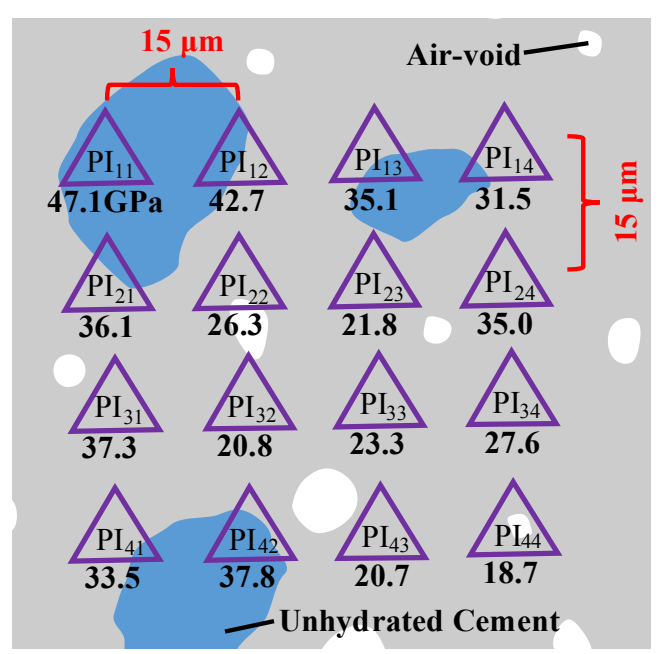

(a) Before Pumping

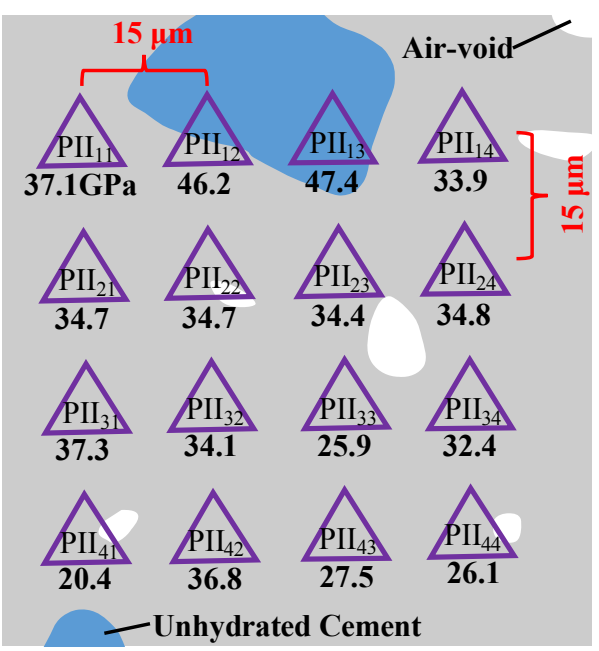

(b) After Pumping

Fig. 13 Nanoindentation results of paste. 
values of each nanoindentation point are marked on the sketch map. It was observed that the elastic modulus of the area with voids was lower than the matrix whereas the elastic modulus of the area with the unhydrated cement was higher than the matrix (Constantinides and Ulm 2004). The maximum elastic modulus of the nanoindentation point before pumping was $47.1 \mathrm{GPa}$ and the minimum was $18.7 \mathrm{GPa}$, indicating the average value was $30.9 \mathrm{GPa}$ with the standard deviation of 8.2. After pumping, the maximum elastic modulus of the nanoindentation point was $47.4 \mathrm{GPa}$ and the minimum was 20.4 $\mathrm{GPa}$. Therefore, the average value was $34.0 \mathrm{GPa}$ with the standard deviation of 6.7. Compared with before pumping, the average elastic modulus of the paste after pumping increased by $10.03 \%$.

Figure 14 is the nanoindentation map of the sand ITZ of the pumping concrete. The elastic modulus of the sand was in the range 50 to $77 \mathrm{GPa}$. The average elastic modulus of the sand was $65.6 \mathrm{GPa}$. It can be seen from Fig. 14 that the elastic modulus of the ITZ (dark gray) was lower than the sand aggregate (blue) and the paste (light gray). The minimum and maximum elastic moduli of the ITZ before pumping [Fig. 14(a)] were $12.9 \mathrm{GPa}$ and $27.7 \mathrm{GPa}$ with the average value of $19.7 \mathrm{GPa}$ and the standard deviation of 4.1. After pumping [Fig. 14 (b)], the minimum elastic modulus of the ITZ was $17.7 \mathrm{GPa}$ and the maximum value was $35.3 \mathrm{GPa}$. The average value was $26.1 \mathrm{GPa}$ and the standard deviation was 4.6. Therefore, the average elastic modulus of the ITZ after pumping was higher than that before pumping.

Figure 15 is the nanoindentation map of the gravel ITZ of the pumping concrete. The elastic modulus of the gravel was within the range 35 to $55 \mathrm{GPa}$, and the average elastic modulus of the gravel was $41.9 \mathrm{GPa}$. The minimum elastic modulus of the ITZ before pumping [Fig. 15(a)] was $12.8 \mathrm{GPa}$ and the maximum value was $27.2 \mathrm{GPa}$ with an average value of $20.0 \mathrm{GPa}$ and a standard deviation of 4.2. The minimum elastic modulus of the gravel ITZ after pumping [Fig. 15(b)] was 19.0 $\mathrm{GPa}$ and the maximum value was $35.9 \mathrm{GPa}$ with a mean

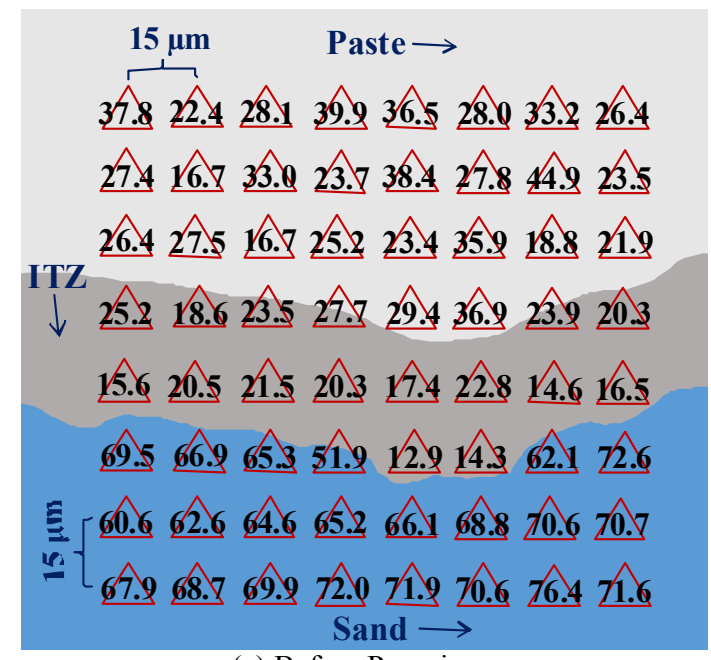

(a) Before Pumping

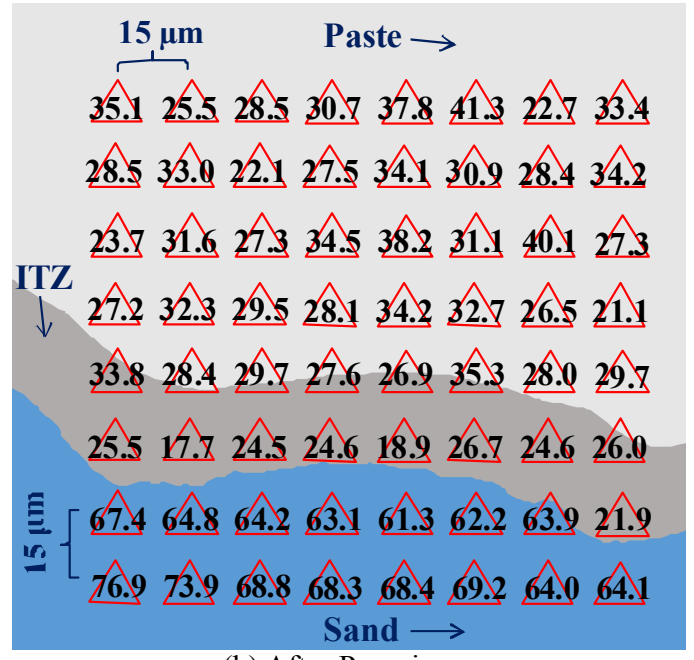

(b) After Pumping

Fig. 14 Nanoindentation results of sand ITZ.

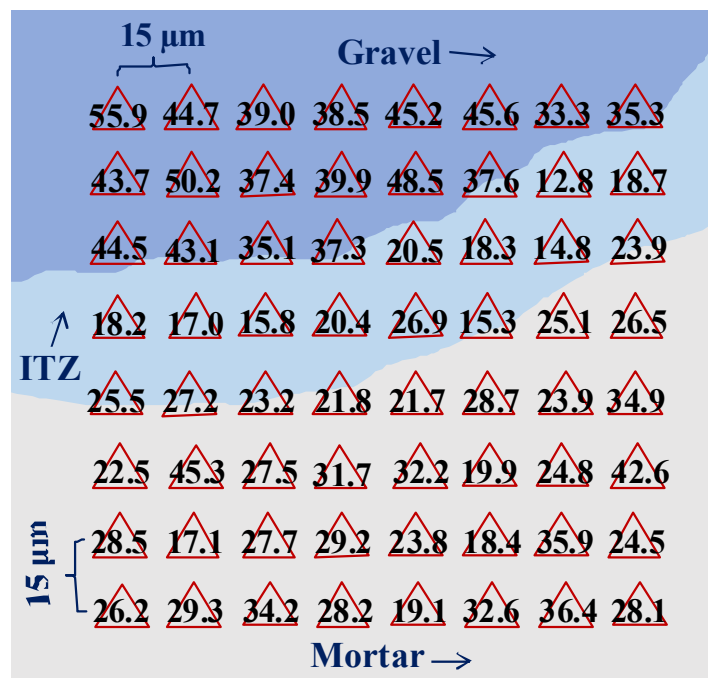

(a) Before Pumping

Fig. 15 Nanoindentation results of gravel ITZ.

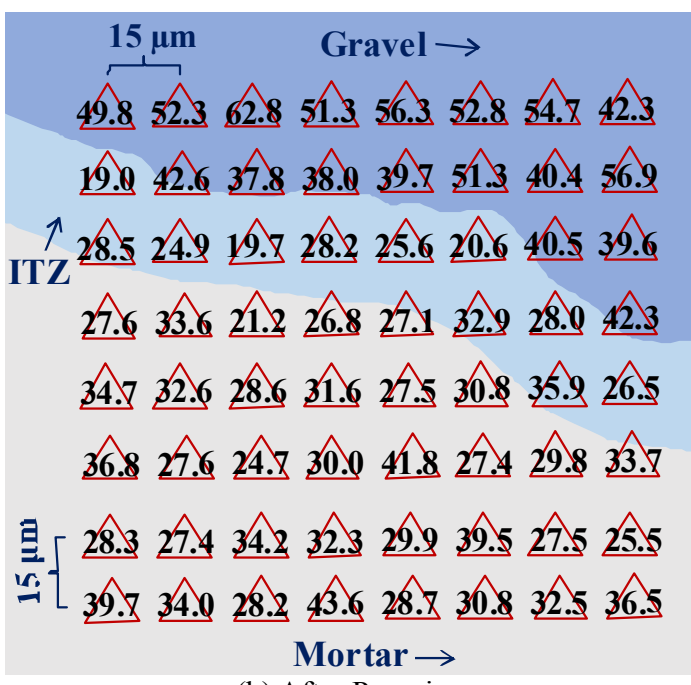

(b) After Pumping 
Table 4 Atomic ratio of nanoindentation points (\%).

\begin{tabular}{ccccccccc}
\hline \multirow{2}{*}{ Points } & \multicolumn{3}{c}{ Before Pumping } & \multicolumn{3}{c}{ After Pumping } \\
\cline { 2 - 7 } & $\mathrm{PI}_{12}$ & $\mathrm{PI}_{22}$ & $\mathrm{PI}_{24}$ & $\mathrm{PI}_{31}$ & $\mathrm{PII}_{11}$ & $\mathrm{PII}_{21}$ & $\mathrm{PII}_{22}$ \\
\hline $\mathrm{O}$ & 64.31 & 67.94 & 68.38 & 68.59 & 66.17 & 67.84 & 68.62 \\
$\mathrm{Si}$ & 10.49 & 14.40 & 11.93 & 9.98 & 16.30 & 16.05 & 13.61 \\
$\mathrm{Ca}$ & 22.30 & 11.68 & 14.5 & 17.99 & 7.52 & 10.76 & 16.06 & 13.77 \\
$\mathrm{Al}$ & 2.89 & 5.98 & 5.19 & 3.43 & 10.01 & 5.35 & 1.70 & 3.67 \\
\hline
\end{tabular}

Table 5 Physical properties of compositions of paste.

\begin{tabular}{|c|c|c|c|c|}
\hline Composition & $\begin{array}{l}\text { Molar mass } \\
(\mathrm{g} / \mathrm{mol})\end{array}$ & $\begin{array}{l}\text { Density } \\
\left(\mathrm{g} / \mathrm{cm}^{3}\right)\end{array}$ & $\begin{array}{l}\text { Bulk modulus } \\
\text { (GPa) }\end{array}$ & $\begin{array}{c}\text { Shear modulus } \\
(\mathrm{GPa})\end{array}$ \\
\hline $3 \mathrm{Al}_{2} \mathrm{O}_{3} \cdot 2 \mathrm{SiO}_{2}$ (Botero et al. 2012) & 426 & 3.16 & 63.62 & 40.39 \\
\hline $\mathrm{SiO}_{2}$ (Gregorová et al. 2015) & 60 & 2.20 & 32.60 & 19.10 \\
\hline $\mathrm{Ca}(\mathrm{OH})_{2}$ (Toropov and Leszczynski 2006) & 74 & 2.24 & 40.79 & 17.75 \\
\hline $3 \mathrm{CaO} \cdot 2 \mathrm{SiO}_{2} \cdot 5 \mathrm{H}_{2} \mathrm{O}($ Haecker et al. 2005) & 378 & 2.65 & 17.64 & 11.10 \\
\hline $2 \mathrm{CaO} \cdot \mathrm{SiO}_{2}(\mathrm{Constantinides}$ and Ulm 2004$)$ & 172 & 2.31 & 42.50 & 15.70 \\
\hline Pores & 0 & 0.00 & 0.00 & 0.00 \\
\hline
\end{tabular}

value of $27.0 \mathrm{GPa}$ and a standard deviation of 4.8 . Therefore, the elastic modulus of the gravel ITZ increased obviously after the ultra-high-rise pumping behavior.

To sum up, the elastic moduli of the paste, sand ITZ and gravel ITZ increased after ultra-high-rise pumping by $14.2 \%, 32.5 \%$ and $35.0 \%$. In addition, it was observed that the ultra-high-rise pumping effect on the elastic modulus of the ITZ was much higher than that of the paste.

The air bubbles and free water in the concrete were easily broken and migrated under ultra-high-rise pumping. Because the content of air bubbles and free water in the ITZ was much higher than that in the paste, the reduction rate of ITZ porosity after pumping was greater than that of the paste. The elastic modulus of ITZ and paste increased with the decrease of porosity, so the increase of elastic modulus of ITZ after pumping was much larger than that of paste.

\subsection{Compositions analysis}

Ulm et al. (2007) used statistical nanoindentation analysis to determine the relative volume fraction of the phase in cement-based materials. However, using this method to calculate the volume fraction of phase in ITZ requires tremendous experiments. In this paper, based on the EDS test results of matrix and ITZ, the volume fraction of each phase was calculated, then the elastic modulus was calculated by homogenization method, and finally compared with the nano indentation test results to verify the reliability of the calculation results.

Through the XRD analysis, it was confirmed that there were $\mathrm{Ca}(\mathrm{OH})_{2}, 2 \mathrm{CaO} \cdot \mathrm{SiO}_{2}, 3 \mathrm{Al}_{2} \mathrm{O}_{3} \cdot 2 \mathrm{SiO}_{2}$ and $\mathrm{SiO}_{2}$ in the paste of the pumping concrete. There were certainly a large number of the C-S-H gels in the hydration products. According to literature (L'Hôpital et al. 2016), the chemical equation of the $\mathrm{C}-\mathrm{S}-\mathrm{H}$ gel in this paper was determined as $3 \mathrm{CaO} \cdot 2 \mathrm{SiO}_{2} \cdot 5 \mathrm{H}_{2} \mathrm{O}$. The atomic percentages of the nanoindentation points in the paste and the ITZ were obtained by the BSE-EDS test, and then the volume fractions of the phases at those points were calculated. Among them, the volume ratios of the unhydrated cement particles and pore were directly calculated by binarization analysis of the BSE image. After removing the corresponding element content of the unhydrated cement particles, the molecular ratios of the other four components were calculated by establishing a linear equation system with four unknowns (Li et al. 2017), as shown in Eq. (6).

$$
\left[\begin{array}{cccc}
13 & 2 & 2 & 12 \\
2 & 1 & 0 & 2 \\
0 & 0 & 1 & 3 \\
6 & 0 & 0 & 0
\end{array}\right] \times\left[\begin{array}{l}
x_{1} \\
x_{2} \\
x_{3} \\
x_{4}
\end{array}\right]=\left[\begin{array}{c}
R_{\mathrm{O}} \\
R_{\mathrm{Si}} \\
R_{\mathrm{Ca}} \\
R_{\mathrm{Al}}
\end{array}\right]
$$

where $x_{1}, x_{2}, x_{3}$ and $x_{4}$ represent the molecular percentages of the four components, which are $3 \mathrm{Al}_{2} \mathrm{O}_{3} \cdot 2 \mathrm{SiO}_{2}$, $\mathrm{SiO}_{2}, \mathrm{Ca}(\mathrm{OH})_{2}$ and $3 \mathrm{CaO} \cdot 2 \mathrm{SiO}_{2} \cdot 5 \mathrm{H}_{2} \mathrm{O}$, respectively. $R_{\mathrm{O}}$, $R_{\mathrm{Si}}, R_{\mathrm{Ca}}$ and $R_{\mathrm{Al}}$ represent the atomic percentage of four elements $(\mathrm{O}, \mathrm{Si}, \mathrm{Ca}$ and $\mathrm{Al})$. The coefficients of the equation correspond to the atomic contents of the corresponding elements in the four chemical equations. For example, in the first row of the coefficient matrix, 13 represents that there are $13 \mathrm{O}$ atoms in $3 \mathrm{Al}_{2} \mathrm{O}_{3} \cdot 2 \mathrm{SiO}_{2}, 2$ represents that there are two $\mathrm{O}$ atoms in $\mathrm{SiO}_{2}, 2$ represents that there are two $\mathrm{O}$ atoms in $\mathrm{Ca}(\mathrm{OH})_{2}$ and 12 represents that there are $12 \mathrm{O}$ atoms in $3 \mathrm{CaO} \cdot 2 \mathrm{SiO}_{2} \cdot 5 \mathrm{H}_{2} \mathrm{O}$.

After obtaining the molecular ratios of components of the nanoindentation point, the mass ratio of the four components were calculated based on the molar mass of each component. In the case of determining the density of each component, the volume fraction of the nanoindentation point can be calculated by dividing the mass of each component by its density. Table 4 lists the atomic percentages of the eight nanoindentation points of the paste before and after pumping in Fig. 13. Table 5 lists the molar mass, density and related mechanical properties of each component. 
Table 6 Volume fractions of compositions on nanoindentation points (\%).

\begin{tabular}{ccccccccc}
\hline \multirow{2}{*}{ Points } & \multicolumn{4}{c}{ Before Pumping } & \multicolumn{3}{c}{ After Pumping } \\
\cline { 2 - 8 } & $\mathrm{PI}_{12}$ & $\mathrm{PI}_{22}$ & $\mathrm{PI}_{24}$ & $\mathrm{PI}_{31}$ & $\mathrm{PII}_{11}$ & $\mathrm{PII}_{21}$ & PII $_{22}$ & $\mathrm{PII}_{44}$ \\
\hline $3 \mathrm{Al}_{2} \mathrm{O}_{3} \cdot 2 \mathrm{SiO}_{2}$ & 6.83 & 13.68 & 14.03 & 8.85 & 24.40 & 13.55 & 4.30 & 8.66 \\
$\mathrm{SiO}_{2}$ & 3.11 & 15.54 & 8.08 & 4.17 & 27.95 & 24.81 & 19.40 & 12.18 \\
$\mathrm{Ca}(\mathrm{OH})_{2}$ & 25.26 & 4.93 & 11.52 & 25.53 & 7.98 & 5.46 & 22.21 & 4.50 \\
$3 \mathrm{CaO} \cdot 2 \mathrm{SiO}_{2} \cdot 5 \mathrm{H}_{2} \mathrm{O}$ & 28.09 & 49.45 & 66.37 & 61.45 & 27.33 & 49.80 & 54.09 & 62.15 \\
$2 \mathrm{CaO} \cdot \mathrm{SiO}_{2}$ & 36.71 & 0.00 & 0.00 & 0.00 & 0.00 & 0.00 & 0.00 & 0.00 \\
Pores & 0.00 & 16.40 & 0.00 & 0.00 & 12.34 & 6.37 & 0.00 & 12.51 \\
\hline
\end{tabular}

Table 7 Volume fractions of compositions of paste (\%).

\begin{tabular}{|c|c|c|c|c|c|c|}
\hline \multirow{2}{*}{ Compositions } & \multicolumn{2}{|c|}{ Paste } & \multicolumn{2}{|c|}{ Sand ITZ } & \multicolumn{2}{|c|}{ Gravel ITZ } \\
\hline & Before & After & Before & After & Before & After \\
\hline $3 \mathrm{Al}_{2} \mathrm{O}_{3} \cdot 2 \mathrm{SiO}_{2}$ & 12.36 & 11.25 & 11.76 & 5.16 & 10.52 & 6.38 \\
\hline $\mathrm{SiO}_{2}$ & 10.13 & 14.23 & 6.69 & 7.41 & 6.56 & 8.46 \\
\hline $\mathrm{Ca}(\mathrm{OH})_{2}$ & 9.61 & 10.66 & 8.03 & 5.26 & 8.83 & 6.12 \\
\hline $3 \mathrm{CaO} \cdot 2 \mathrm{SiO}_{2} \cdot 5 \mathrm{H}_{2} \mathrm{O}$ & 44.39 & 54.69 & 50.39 & 74.82 & 50.81 & 72.10 \\
\hline $2 \mathrm{CaO} \cdot \mathrm{SiO}_{2}$ & 11.78 & 4.71 & 0.00 & 0.00 & 0.00 & 0.00 \\
\hline Pores & 11.73 & 4.46 & 23.13 & 7.35 & 23.28 & 6.94 \\
\hline
\end{tabular}

The volume fractions of the $2 \mathrm{CaO} \cdot \mathrm{SiO}_{2}$ and pores at the nanoindentation point were determined by the BSE binarization analysis. After removing the atomic percentage of the $2 \mathrm{CaO} \cdot \mathrm{SiO}_{2}$, the volume fractions of the other four substances were calculated. Table $\mathbf{6}$ is the volume fractions of the 6 constituents of the 8 nanoindentation points in Fig. 13.

According to the analysis results of 128 nanoindentation points in the paste before and after pumping, the volume fractions of four components $\left(3 \mathrm{Al}_{2} \mathrm{O}_{3} \cdot 2 \mathrm{SiO}_{2}\right.$, $\mathrm{SiO}_{2}, \mathrm{Ca}(\mathrm{OH})_{2}$ and $\left.3 \mathrm{CaO} \cdot 2 \mathrm{SiO}_{2} \cdot 5 \mathrm{H}_{2} \mathrm{O}\right)$ in paste before and after pumping were taken as the average of 64 nanoindentation points, respectively, and the contents of the $2 \mathrm{CaO} \cdot \mathrm{SiO}_{2}$ and pores were determined by the $\mathrm{BSE}$ image binarization in Section 3.2. The calculation method for the volume fraction of each component in the ITZ was the same as the paste. The volume contents of the components in the paste and the ITZ before and after pumping are shown in Table 7 (Hu et al. 2017b). After pumping, the $\mathrm{C}-\mathrm{S}-\mathrm{H}$ in the paste increased significantly by $10.3 \%$, the $\mathrm{SiO}_{2}$ and $\mathrm{Ca}(\mathrm{OH})_{2}$ increased slightly, while the $3 \mathrm{Al}_{2} \mathrm{O}_{3} \cdot 2 \mathrm{SiO}_{2}$ decreased slightly. Compared with the paste, the content of the C-S-H in the ITZ increased, and the content of the C-S-H in the ITZ after pumping was up to $70 \%$. There were no unhydrated cement particles in the ITZ.

\section{Evaluation of elastic modulus of concrete by homogenization}

The static compressive elasticity modulus test of concrete can only measure the modulus of elasticity of concrete at macro level, while the effect of ultra-high-rise pumping on the mechanical properties and components of concrete was mainly reflected at micro level. The homogenization method can be used to calculate the micro, meso and macro elastic modulus of the ultra-high-rise pumping concrete, then studied the influence of the ultra-high-rise pumping on the micro, meso and macro elastic modulus of the concrete.

In this section, the elastic moduli of the paste and ITZ before and after pumping were calculated by homogenization method of which the reliability was verified by comparing with the results of the nanoindentation on the micro scale. Then the Lu and Torquato model was used to calculate the volume fraction of each phase of the pumping concrete on the meso and macro scales. Afterward, the homogenization method was used to predict the elastic modulus of the concrete after ultra-high-rise pumping on the meso and macro scales. Combining the BSE-EDS test with the Lu and Torquato model, the validity of the homogenization method for calculating elastic modulus of the ultra-high-rise pumping concrete was verified, and the pumping influence on the elastic modulus of the concrete on micro-meso-macro scales was clarified.

\subsection{Homogenization method}

For concrete materials, Self-Consistent (SC) was a common homogenization method (Budiansky 1965; Hill 1965). This method did not need to distinguish the difference in morphology between inclusions and matrix. That is to say, this method was suitable for composite materials whose reference medium was difficult to determine. According to the multi-scale method proposed by Ulm (Constantinides and Ulm 2004) and the characteristics of the hydration products in this paper, concrete can be divided into three levels, as shown in Fig. 16. After determining the volume fraction of each component in the paste and the elastic modulus of the ITZ, the elastic modulus of the concrete after pumping can be predicted by the SC method on micro-meso-macro scale.

In the first scale (Level I), the paste contained C-S-H gel, $\mathrm{CH}$ crystal, unhydrated cement particle, $\mathrm{SiO}_{2}$, $3 \mathrm{Al}_{2} \mathrm{O}_{3} \cdot 2 \mathrm{SiO}_{2}$, and pore with the characteristic length range $10^{-6}$ to $10^{-4} \mathrm{~m}$. On this scale, it was difficult to distinguish the matrix from the inclusion due to the complexity of each component at the nanoindentation 
point and the variability of the volume fraction. Therefore, the elastic modulus of the nanoindentation point was calculated by the SC method (Hill 1965). According to the bulk modulus, shear modulus and volume fraction of each component at each nanoindentation point in Table 5, the bulk modulus and shear modulus of each nanoindentation point on the paste of the pumping concrete can be calculated by Eqs. (7) and (8).

$$
\begin{gathered}
k^{\text {hom }}=k_{0}+\sum_{r=1}^{N} \frac{c_{r}\left(k_{r}-k_{0}\right)\left(3 k^{\text {hom }}+4 \mu^{\text {hom }}\right)}{3 k_{r}+4 \mu^{\text {hom }}} \\
\mu^{\text {hom }}=\mu_{0}+\sum_{r=1}^{N} \frac{5 c_{r} \mu^{\text {hom }}\left(\mu_{r}-\mu_{0}\right)\left(3 k^{\text {hom }}+4 \mu^{\text {hom }}\right)}{3 k^{\text {hom }}\left(3 \mu^{\text {hom }}+2 \mu_{r}\right)+4 \mu^{\text {hom }}\left(2 \mu^{\text {hom }}+3 \mu_{r}\right)}
\end{gathered}
$$

where $k^{\text {hom }}$ and $\mu^{\text {hom }}$ represent bulk modulus and shear modulus, respectively. The elastic modulus $E^{\text {hom }}$ of the paste and the ITZ can be calculated by Eq. (9).

$$
E^{\text {hom }}=\frac{9 k^{\text {hom }} \mu^{\text {hom }}}{3 k^{\text {hom }}+\mu^{\text {hom }}}
$$

The second scale (Level II) regarded the paste as the matrix phase of the mortar, ITZ and sand aggregate as the inclusions. The elastic moduli of the paste and ITZ were calculated using the above calculation results from Level I. The nanoindentation test value of the sand was used as the elastic modulus of the sand aggregate in this paper $(65.6 \mathrm{GPa})$. The elastic modulus of the mortar was calculated by the SC method [Eqs. (7) and (8)].

The third scale (Level III) took the mortar as the matrix phase of the concrete, the ITZ and gravel aggregate as the inclusions. The elastic moduli of the mortar and the ITZ were calculated from Level II, and the elastic modulus of the gravel was measured by the nanoindentation test (41.9 GPa). Then the SC method [Eqs. (7) and

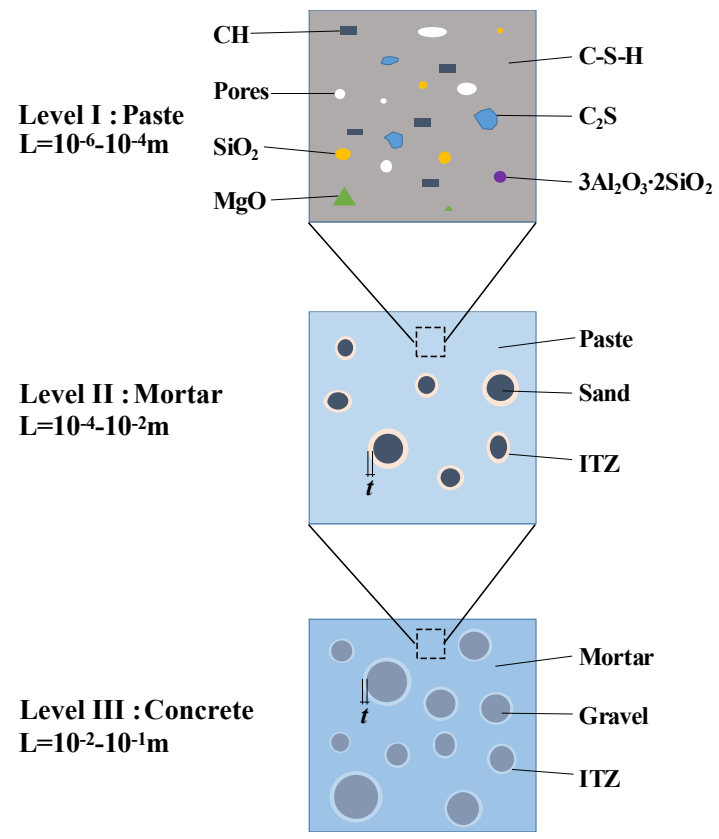

Fig. 16 Multiscale microstructure of concrete.
(8)] was used to calculate the elastic modulus of the pumping concrete.

\subsection{Calculation of volume fraction of phases}

The volume fraction of the sand in the mortar can be calculated according to the design value of the mix ratio of the pumping concrete, Eq. (10).

$$
\begin{aligned}
f_{s} & =\frac{v_{s}}{v_{s}+v_{w}+v_{c}+v_{f a}+v_{s f}+v_{s p}} \\
& =\frac{m_{s} / \rho_{s}}{m_{s} / \rho_{s}+m_{w} / \rho_{w}+m_{c} / \rho_{c}+m_{f a} / \rho_{f a}+m_{s f} / \rho_{s f}+m_{s p} / \rho_{s p}}
\end{aligned}
$$

where $f_{s}$ is the volume fraction of the sand in the mortar, $v_{s}$ is the volume of the sand in the mortar, $v_{w}, v_{c}, v_{f a}, v_{s f}$ and $v_{s p}$ are the volumes of the initial water, cement, fly ash, silica fume and micro-mineral powder in the mortar, $m_{w}, m_{c}, m_{f a}, m_{s f}$ and $m_{s p}$ are the mass of the water, cement, fly ash, silica fume and micro-mineral powder. $\rho_{s}, \rho_{w}, \rho_{c}$, $\rho_{f a}, \rho_{s f}$ and $\rho_{s p}$ are the density of the water, cement, fly ash, silica fume and micro-mineral powder, respectively.

According to the mix ratio of the mortar and the density of the sand aggregate, water, cement, fly ash, silica fume and micro-mineral powder $\left(\rho_{s}=2.62 \mathrm{~g} / \mathrm{cm}^{3}, \rho_{w}=\right.$ $1.00 \mathrm{~g} / \mathrm{cm}^{3}, \rho_{c}=3.10 \mathrm{~g} / \mathrm{cm}^{3}, \rho_{f a}=2.78 \mathrm{~g} / \mathrm{cm}^{3}, \quad \rho_{s f}=2.20$ $\mathrm{g} / \mathrm{cm}^{3}, \quad \rho_{s p}=2.81 \mathrm{~g} / \mathrm{cm}^{3}$ ), the volume fraction of the sand aggregate in the mortar sample was calculated as $f_{s}=$ $51.19 \%$.

The $\mathrm{Lu}$ and Torquato model was used to calculate the volume fraction of the ITZ (Garboczi and Bentz 1997), as shown in Fig. 17. The overlapping of the ITZ between the adjacent aggregates was considered in this model. Its basic assumption was that the sand aggregate was a circular particle and the ITZ was a shell with a thickness of $t$, wrapping around the circular sand aggregate. The volume fraction of the cement paste was considered as the left area except the sand aggregate and the ITZ.

When the model was applied to the mortar, the volume fraction of the cement paste matrix can be defined as $e_{v}(t)$, assuming that the spherical particles of different scales were randomly distributed in the cement paste matrix. Thus, if the thickness of the ITZ was infinite, i.e., $t \rightarrow \infty$, the area occupied by the paste in the mortar tended to be 0 . Based on the above assumptions, the volume fraction of the ITZ can be expressed as:

$$
f_{I T Z}=1-f_{s}-e_{v}(t)
$$

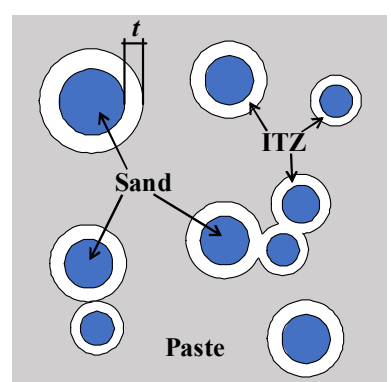

Fig. 17 Schematic diagram of the Lu and Torquato model. 
Table 8 Calculated elastic modulus (GPa) of nanoindentation points.

\begin{tabular}{|c|c|c|c|c|c|c|c|c|c|}
\hline \multirow{2}{*}{$\mathrm{PI} I_{\mathrm{ij}}$} & \multicolumn{4}{|c|}{ Before Pumping } & \multirow{2}{*}{$\mathrm{PII}_{\mathrm{ij}}$} & \multicolumn{4}{|c|}{ After Pumping } \\
\hline & $\mathrm{PI}_{\mathrm{i} 1}$ & $\mathrm{PI}_{\mathrm{i} 2}$ & $\mathrm{PI}_{\mathrm{i} 3}$ & $\mathrm{PI}_{\mathrm{i} 4}$ & & $\mathrm{PII}_{\mathrm{i} 1}$ & $\mathrm{PII}_{\mathrm{i} 2}$ & $\mathrm{PII}_{\mathrm{i} 3}$ & $\mathrm{PII}_{\mathrm{i} 4}$ \\
\hline$P I_{1 j}$ & 46.3 & 40.8 & 33.8 & 32.6 & $\mathrm{PII}_{1 \mathrm{j}}$ & 36.5 & 43.7 & 44.9 & 32.1 \\
\hline$P I_{2 j}$ & 34.6 & 25.4 & 22.4 & 36.3 & $\mathrm{PII}_{2 \mathrm{j}}$ & 34.1 & 36.4 & 36.0 & 33.4 \\
\hline$P I_{3 j}$ & 35.9 & 21.6 & 22.6 & 28.9 & $\mathrm{PII}_{3 \mathrm{j}}$ & 35.5 & 34.8 & 27.5 & 34.4 \\
\hline $\mathrm{PI}_{4 \mathrm{j}}$ & 34.4 & 35.5 & 21.9 & 17.5 & $\mathrm{PII}_{4 \mathrm{j}}$ & 19.6 & 36.2 & 28.1 & 25.5 \\
\hline
\end{tabular}

The following equation was obtained by substituting the thickness $t$ of the ITZ and the size distribution of the sand aggregate.

$e_{v}(t)=\left(1-f_{s}\right) \exp \left\{-2 f_{s} S\left[a_{0}\left(\frac{t}{\overline{D_{N}}}\right)^{3}+a_{1}\left(\frac{t}{\overline{D_{N}}}\right)^{2}+a_{2}\left(\frac{t}{\overline{D_{N}}}\right)^{2}\right]\right\}, \quad t \geq 0($

where $\mathrm{t}$ is the thickness of the ITZ, $a_{0}=\left[4 B\left(1-f_{s}\right)\left(1-f_{s}+3 f_{s} S\right)+4 A f_{s}^{2} S^{2}\right] /\left(1-f_{s}\right)^{3}, \mathrm{~A}$ is a constant, usually 0,2 or 3 . Assuming that the sand aggregate is circular, $\mathrm{A}=0$ is the best choice, $a_{1}=\left[6 B\left(1-f_{s}\right)+9 f_{s} S\right] /\left(1-f_{s}\right)^{2} \quad ; \quad a_{2}=3 /\left(1-f_{s}\right)$, $B=\left(\overline{D_{N}}\right)^{2} / \overline{D_{N}^{2}}, S=\left(\overline{D_{N}^{2}} \times \overline{D_{N}}\right)^{2} / \overline{D_{N}^{3}}, \overline{D_{N}}$ is the average diameter of aggregate quantity, $\overline{D_{N}^{2}}$ is the second-order origin moment of the average diameter of aggregate quantity and $\overline{D_{N}^{3}}$ is the third-order origin moment of the average diameter of aggregate quantity.

The volume fraction of the paste in the mortar can be calculated according to the following equation:

$$
f_{c}=1-f_{s}-f_{\text {ITZ }}
$$

The thickness of the sand ITZ before pumping was $28.47 \mu \mathrm{m}$. The volume fractions of the ITZ and the paste in the mortar before pumping were $20.42 \%$ and $28.39 \%$, respectively by using Eqs. (10), (11), (12) and (13). The thickness of the sand ITZ after pumping was $23.17 \mu \mathrm{m}$, so the volume fraction of the ITZ and the paste were $16.12 \%$ and $32.69 \%$, respectively.

The density of the gravel was $2.70 \mathrm{~g} / \mathrm{cm}^{3}$. The volume fraction of the coarse aggregate in the pumping concrete was $37.58 \%$ by using the same calculation method with Eq. (10). The thickness of the gravel ITZ before pumping was $29.69 \mu \mathrm{m}$, and the volume fractions of the ITZ and the mortar in the concrete before pumping were calculated by Eqs. (11), (12) and (13), which were $1.35 \%$ and $61.07 \%$, respectively. After pumping, the thickness of the gravel ITZ was $22.78 \mu \mathrm{m}$, and the volume fractions of the ITZ and the mortar were $1.16 \%$ and $61.25 \%$, respectively.

\subsection{Calculation of elastic modulus of pumping concrete}

According to Eq. (6), the volume fraction of each component at each nanoindentation point in Fig. 13 was calculated, and then the elastic modulus of the paste in the pumping concrete, i.e., the elastic modulus of Level I, was calculated by Eqs. (7) and (8). The calculated elastic moduli of partial nanoindentation points before and after pumping are shown in Table 8.

In Table 8, the calculated elastic moduli of the paste before and after pumping were close to that from the nanoindentation test (Fig. 13). The average relative errors of the elastic modulus of the paste before and after pumping were $3.98 \%$ and $3.89 \%$, respectively. According to the volume fraction of each component in Table 7, the elastic modulus of the paste (Level I) before and after pumping was calculated by Eqs. (7), (8) and (9), which were $29.6 \mathrm{GPa}$ and $33.9 \mathrm{GPa}$, respectively.

The elastic modulus of the ITZ of the pumping concrete in Table 7 was calculated by Eqs. (7) and (8). The calculated elastic modulus of the sand ITZ before pumping was $19.2 \mathrm{GPa}$ with a relative error of $2.54 \%$, compared with the results from the nanoindentation test. The calculated elastic modulus of the sand ITZ after pumping was $26.9 \mathrm{GPa}$ with a relative error of $3.07 \%$. The calculated elastic modulus of the gravel ITZ before pumping was $18.8 \mathrm{GPa}$ with a relative error of $6.00 \%$. The calculated elastic modulus of gravel ITZ after pumping was $27.9 \mathrm{GPa}$ with a relative error of $3.33 \%$.

According to the test results of the nanoindentation, the elastic modulus of the sand was $65.6 \mathrm{GPa}$. Besides, the Poisson's ratio of the sand was 0.15 ( $\mathrm{Li}$ et al. 1999). The shear modulus and bulk modulus of the sand calculated by Eqs. (14) and (15) were 28.5 GPa and 31.2 GPa, respectively.

$$
\begin{aligned}
& \mu=\frac{E}{2(1+v)} \\
& k=\frac{E}{3(1-2 v)}
\end{aligned}
$$

According to the homogenized elastic modulus calculation results of the paste mentioned above (Level I), the shear modulus and bulk modulus of the paste before pumping were calculated using Eqs. (14) and (15) as 11.8 $\mathrm{GPa}$ and 19.7 GPa, respectively, with the Poisson's ratio of the paste being 0.25 ( $\mathrm{Li}$ et al. 1999). The shear modulus and bulk modulus of the paste after pumping were 13.6 GPa and 22.6 GPa. The shear modulus and bulk modulus of the sand ITZ before pumping were 7.4 $\mathrm{GPa}$ and 16.0 GPa, respectively according to Eqs. (14) and (15), and the shear modulus and bulk modulus of the sand ITZ after pumping were $10.3 \mathrm{GPa}$ and $22.4 \mathrm{GPa}$, respectively, and the Poisson's ratio of the ITZ was 0.3 (Li et al. 1999).

Based on the volume fraction of the paste, ITZ and sand in the pumping concrete in Section 4.2, the elastic moduli of the mortar (Level II) before and after pumping 
Table 9 Calculation results of elastic modulus of concrete before and after pumping.

\begin{tabular}{cccc}
\hline & Theoretical Value & Experimental Value & Relative Errors \\
\hline Before Pumping & $40.8 \mathrm{GPa}$ & $39.9 \mathrm{GPa}$ & $2.26 \%$ \\
After Pumping & $44.2 \mathrm{GPa}$ & $43.3 \mathrm{GPa}$ & $2.08 \%$ \\
\hline
\end{tabular}

were calculated by using Eqs. (7) and (8), which were 40.7 GPa and 46.1 GPa, respectively.

The elastic modulus of the gravel from the nanoindentation test was $41.9 \mathrm{GPa}$. The shear modulus and bulk modulus of the gravel calculated by Eqs. (14) and (15) were $17.5 \mathrm{GPa}$ and $23.3 \mathrm{GPa}$, respectively, and the Poisson's ratio of the gravel was 0.20 (Li et al. 1999). According to the calculation results of the elastic modulus of the mortar in Level II, the shear modulus and bulk modulus of the mortar before pumping were 16.8 $\mathrm{GPa}$ and $23.4 \mathrm{GPa}$, while the shear modulus and bulk modulus of the mortar after pumping were $19.0 \mathrm{GPa}$ and 26.5 GPa respectively and the Poisson's ratio of mortar was 0.21 ( $\mathrm{Li}$ et al. 1999). According to the calculation results of the homogenization method for elastic modulus of the gravel ITZ in the pumping concrete, the shear modulus and bulk modulus of the gravel ITZ before pumping were $7.2 \mathrm{GPa}$ and $15.7 \mathrm{GPa}$, respectively. Those two values of the ITZ after pumping were 10.7 $\mathrm{GPa}$ and $23.2 \mathrm{GPa}$, respectively.

According to the volume fraction, the shear modulus and the bulk modulus of the mortar, ITZ and gravel in Level III, the elastic modulus of the pumping concrete was predicted by the homogenization method [Eqs. (7) and (8)]. The calculation results of elastic modulus of concrete before and after pumping are shown in Table 9. The elastic modulus of the concrete before pumping was $40.8 \mathrm{GPa}$ and after pumping, that was $44.2 \mathrm{GPa}$. The relative errors between the experimental and theoretical values of the elastic modulus of the concrete samples before and after pumping were $2.26 \%$ and $2.08 \%$, respectively.

The calculated results of the elastic modulus of the paste and ITZ obtained by combining the BSE image analysis method with the SC method were of high accuracy to those obtained by the nanoindentation test. Then the elastic modulus of the ultra-high-rise pumping concrete can be predicted promisingly on multi-scale by combining the SC method with the $\mathrm{Lu}$ and Torquato model.

The homogenization method was used to calculate accurately the elastic modulus of concrete at micro, meso and macro scales before and after pumping. The relationship between the micro elastic modulus and the macro elastic modulus of the concrete was established, and the influence of the ultra-high-rise pumping action on the concrete elastic modulus at micro, meso and macro scales was accurately analyzed.

\section{Conclusions}

Based on the engineering test of the pumping concrete, the pumping influence on the composition and microstructure of the concrete was studied. The elastic modulus of the pumping concrete was calculated by the homogenization method on multi-scales. The following conclusions are drawn from the test and the analysis:

(1) After pumping with a vertical height of $407 \mathrm{~m}$ and a maximum pumping pressure of $19.3 \mathrm{MPa}$, the axial compressive strength and the macroscopic elastic modulus of concrete increased by $7.29 \%$ and $8.52 \%$, respectively.

(2) The BSE image binarization method was used to analyze the ultra-high-rise pumping concrete. After pumping, the porosity of the paste decreased by $7.27 \%$ and the unhydrated cement decreased by $6.51 \%$. The influence of the pumping process on the sand ITZ and the gravel ITZ in concrete was similar. The thickness of the sand ITZ after pumping decreased by $5.3 \mu \mathrm{m}$ and the average porosity of the ITZ decreased by $16.44 \%$. The thickness of the gravel ITZ decreased by $6.91 \mu \mathrm{m}$ and the average porosity of the ITZ decreased by $17.15 \%$. The porosity of the ITZ decreased significantly after pumping.

(3) According to the nanoindentation test results, the elastic moduli of the paste and the ITZ of the pumping concrete increased due to the ultra-high-rise pumping behavior. Compared with before pumping, the elastic modulus of the paste after pumping increased by about $10.03 \%$, that of sand ITZ and gravel ITZ increased by $32.5 \%$ and $35.0 \%$. The effect of the ultra-high-rise pumping on the elastic modulus of the ITZ was much higher than the paste.

(4) According to the BSE image analysis method and the EDS test results, the combination of the SC method and the $\mathrm{Lu}$ and Torquato model can accurately predict the elastic modulus of the concrete after the ultra-high-rise pumping on the micro-meso-macro scale.

\section{Acknowledgements}

The authors would like to acknowledge the financial support by the National Key R\&D Program of China-Key materials and preparation technology of high crack resistant ready-mixed concrete (2017YFB0310100); National Natural Science Foundation of China (51808015).

\section{References}

Botero, C. A., Jimenez-Piqué, E., Seuba, J., Kulkarni, T., Sarin, V. K. and Llanes, L., (2012). "Mechanical behavior of $3 \mathrm{Al}_{2} \mathrm{O}_{3} \cdot 2 \mathrm{SiO}_{2}$ films under nanoindentation." Acta Materialia, 60(16), 5889-5899.

Budiansky, B., (1965). "On the elastic moduli of some heterogeneous materials." Journal of the Mechanics and Physics of Solids, 13(4), 223-227.

Choi, M., Roussel, N., Kim, Y. and Kim, J., (2013). "Lubrication layer properties during concrete 
pumping." Cement and Concrete Research, 45, 69-78.

Choi, M. S., Kim, Y. J., Jang, K. P. and Kwon, S. H., (2014). "Effect of the coarse aggregate size on pipe flow of pumped concrete." Construction and Building Materials, 66, 723-730.

Constantinides, G. and Ulm, F. -J., (2004). "The effect of two types of C-S-H on the elasticity of cement-based materials: results from nanoindentation and micromechanical modeling." Cement and Concrete Research, 34(1), 67-80.

Ede, A. N., (1957). "The resistance of concrete pumped through pipelines." Magazine of Concrete Research, 9(27), 129-140.

Feys, D., De Schutter, G. and Verhoeven, R., (2012). "Parameters influencing pressure during pumping of self-compacting concrete." Materials and Structures, 46(4), 533-555.

Feys, D., Khayat, K. H., Perez-Schell, A. and Khatib, R., (2014). "Development of a tribometer to characterize lubrication layer properties of self-consolidating concrete." Cement and Concrete Composites, 54, 40-52.

Gao, Y., De Schutter, G. and Ye, G., (2013). "Micro- and meso-scale pore structure in mortar in relation to aggregate content." Cement and Concrete Research, $52,149-160$.

Garboczi, E. J. and Bentz, D. P., (1997). "Analytical formulas for interfacial transition zone properties." Advanced Cement Based Materials, 6(97), 99-108.

Gregorová, E., Černý, M., Pabst, W., Esposito, L., Zanelli, C., Hamáček, J. and Kutzendörfer, J., (2015). "Temperature dependence of Young's modulus of silica refractories." Ceramics International, 41(1), 1129-1138.

Haecker, C. J., Garboczi, E. J., Bullard, J. W., Bohn, R. B., Sun, Z., Shah, S. P. and Voigt, T., (2005). "Modeling the linear elastic properties of Portland cement paste." Cement and Concrete Research, 35(10), 1948-1960.

Han, J., Di, J. and Yan, P., (2016). "Understanding the shrinkage compensating ability of type $\mathrm{K}$ expansive agent in concrete." Construction and Building Materials, 116, 36-44.

Han, J., Pan, G. and Wei, S., (2012). "Elastic modulus change investigation of cement paste before and after carbonation using nanoindentation technique." Procedia Engineering, 27(27), 341-347.

Hill, R., (1965). "Theory of mechanical properties of fibre-strengthened materials - III: self-consistent model." Journal of the Mechanics and Physics of Solids, 13(4), 189-198.

Hu, S., Yuan, P., Wang, F., Nie, S. and Liu, Y., (2017a). "Application of backscattered electron imaging and image analysis in the research of pore structure of cement-based material." Journal of Building Materials, 20(02), 316-320 (in Chinese).

$\mathrm{Hu}, \mathrm{X}$. , Ma, X., Dong, X., Cao, C., Du, H. and Chen, Z., (2017b). "The prediction of elastic modulus of the mul- lite fiber network based on the actual structure architecture." Ceramics International, 43(18), 16107-16113.

Kaplan, D., Larrard, F. D. and Sedran, T., (2005). "Design of concrete pumping circuit." ACI Materials Journal, 102(2), 110-117.

Kocaba, V., Gallucci, E. and Scrivener, K. L., (2012). "Methods for determination of degree of reaction of slag in blended cement pastes." Cement and Concrete Research, 42(3), 511-525.

L'Hôpital, E., Lothenbach, B., Kulik, D. A. and Scrivener, K., (2016). "Influence of calcium to silica ratio on aluminium uptake in calcium silicate hydrate." Cement and Concrete Research, 85, 111-121.

Li, G., Zhao, Y. and Pang, S. -S., (1999). "Four-phase sphere modeling of effective bulk modulus of concrete." Cement and Concrete Research, 29(6), 839-845.

Li, Y., Wang, P. and Wang, Z., (2017). "Evaluation of elastic modulus of cement paste corroded in brine solution with advanced homogenization method." Construction and Building Materials, 157, 600-609.

Ortega, J. M., Sánchez, I. and Climent, M. A., (2012). "Influence of different curing conditions on the pore structure and the early age properties of mortars with fly ash and blast-furnace slag." Materiales De Construccion, 63(310), 219-234. (in Spanish)

Qing-Lei, Y. U., Tang, C. A., Zhu, W. C. and Tang, S. B., (2008). "Digital image-based numerical simulation on failure process of concrete." Engineering Mechanics, 25(9), 72-78.

Tan, Y., Zhang, H., Yang, D., Jiang, S., Song, J. and Sheng, Y., (2011). "Numerical simulation of concrete pumping process and investigation of wear mechanism of the piping wall." Tribology International, 46(1), 134-144.

Toropov, A. A. and Leszczynski, J., (2006). "A new approach to the characterization of nanomaterials: predicting Young's modulus by correlation weighting of nanomaterials codes." Chemical Physics Letters, 433(1-3), 125-129.

Ulm, F. -J., Vandamme, M., Bobko, C. and Ortega, J. A., (2007). "Statistical indentation techniques for hydrated nanocomposites: concrete, bone, and shale." Journal of the American Ceramic Society, 90(9), 2677-2692

Wang, X. H., Jacobsen, S., He, J. Y., Zhang, Z. L., Lee, S. F. and Lein, H. L., (2009). "Application of nanoindentation testing to study of the interfacial transition zone in steel fiber reinforced mortar." Cement and Concrete Research, 39(8), 701-715.

Zhao, Q., Sun, W., Zheng, K. and Jiang, G., (2005). "Comparison for elastic modulus of cement, ground granulated blast-furnace slag and fly ash particles." Journal of the Chinese Ceramic Society, 33(7), 837-841.

Zhao, Z., Qu, X., Li, F. and Wei, J., (2018). "Effects of steel slag and silica fume additions on compressive strength and thermal properties of lime-fly ash pastes." Construction and Building Materials, 183, 439-450. 